\title{
MANAGING A DUOPOLISTIC WATER MARKET WITH CONFIRMED PROPOSALS. An experiment
}

\section{GESTIÓN DE UN DUOPOLIO ACUÍFERO CON PROPUESTAS CONFIRMADAS. Un experimento}

\author{
Aurora García-Gallego mgarcia@eco.uji.es \\ Laboratorio de Economía Experimental (LEE) \& Universitat Jaume I. Castellón. Spain. \\ Nikolaos Georgantzís ngeorgantzis@ugr.es \\ Laboratorio de Economía Experimental (LEE). Universitat Jaume I \& Granada Lab of Behavioral Eco- \\ nomics (GLOBE). University of Granada. Spain.
}

ROBERTo HERNÁN-GonZÁLEZ roberto.hernangonzalez@gmail.com

Economic Science Institute de Chapman University. USA

Praveen Kujal kujal@eco.uc3m.es

Carlos III University of Madrid. Spain

\begin{abstract}
We report results from experimental water markets in which owners of two different sources of water supply water to households and farmers. The final water quality consumed by each type of consumer is determined through mixing of qualities from two different resources. We compare the standard duopolistic market structure with an alternative market clearing mechanism inspired by games with confirmed strategies (which have been shown to yield collusive outcomes). As in the static case, complex dynamic markets operating under a confirmed proposals protocol yield less efficient outcomes because coordination among independent suppliers has the usual effects of restricting output and increasing prices to the users. Our results suggest that, when market mechanisms are used to allocate water to its users, the rule of thumb used by competition authorities can also serve as a guide towards water market regulation.
\end{abstract}

\section{KEYWORDS}

Allocation of water; Dynamic duopoly; Endogenous water quality; Games with confirmed proposals.

\section{RESUMEN}

Se presentan resultados de un experimento con mercados acuíferos en el que los propietarios de agua de distinta calidad la ofrecen a hogares y agricultores. La calidad finalmente consumida por cada tipo de consumidor se determina a partir de una mezcla de las dos calidades. Se compara el duopolio estándar con una forma alternativa de cerrar el mercado que está inspirada en los juegos con propuestas confirmadas, que consiguen resultados relativamente más colusivos. Como en el caso estático, los mercados dinámicos y complejos que operan bajo un protocolo de propuestas confirmadas son menos eficientes porque la coordinación entre oferentes independientes tiene los efectos de restringir el output y de provocar un crecimiento de los precios. Nuestros resultados sugieren que cuando los mecanismos de mercado se utilizan para distribuir el agua a sus usuarios, la regla utilizada por parte de las autoridades de la competencia puede servir también como guía para la regulación de los mercados acuíferos.

\section{Palabras clave}

Calidad endógena del agua; Duopolio dinámico; Juegos con propuestas confirmadas. 


\section{INTRODUCTION*}

In its 1993 policy paper (Water Resources Management) the World Bank states that the deterioration and scarcity of fresh water in recent times is due to the "failure to properly consider the economic value of water. Given that water is given little or no economic value it is misallocated and misused". Thus, efficiency in water allocation is becoming of great importance for countries all over the world. The problem is difficult given that historically water has been treated as a social rather than an economic good. A need for a market based mechanism to allocate water efficiently is widely gaining acceptance.

Water is a growing industry worldwide. Recent estimates put the world water market at $\$ 300$ billion, with the United States accounting for more than half that amount. Two of the fastest growing markets are in water rights and municipal water supply systems. The proper definition of property rights and delegation of water allocation to market mechanisms can alone not solve the problem. For example, it has been shown that competitive water withdrawal can lead to overexploitation (Moench, 1992). Gordon (1954), meanwhile, showed that complete rent dissipation may occur from the exploitation of an open access resource, whereas a single owner internalizes exploitation externalities, and would be more efficient. Experiments have been used by Walker,Gardner and Ostrom (1990), Walker and Gardner (1992) and Gardner, Moore, and Walker (1997) to study common pool resource problems. Mason and Philips (1997), for example, provide experimental evidence on the relationship between group size and the standing stock of a common resource. The general result is that there is an inverse relationship between the number of resource extractors and rent accrual.

McCabe, Rassenti and Smith (1991) present a "smart" computer assisted market institution. This mechanism was designed to compute prices and allocations by applying an optimization algorithm that maximizes the possible gains from exchange, given a set of decentralized strategies. Using California as a case study, Murphy et al. (2000) test alternative institutional arrangements for a computer assisted "thin" spot market, showing that the "smart" uniform price double auction yields highly efficient outcomes, and that co-tenancy of pipeline nodes improves efficiency compared to a monopoly.

Apart from identifying important shortcomings of decentralized exploitation of water resources, the studies mentioned above show that experiments can be a useful test bed to study alternative water management mechanisms (Walker, Gardner and Ostrom, 1990; Walker and Gardner, 1992; Murphy et al., 2000). Experiments can replicate important characteristics of existing markets and test them in a laboratory setting at a minimal

\footnotetext{
"Acknowledgements: We gratefully acknowledge financial support by the Spanish Ministry of Science an Technology (ECO 2008-00977/ECON and 2008-04636/ECON), Junta de Andalucía (P07-SEJ-03155), Bancaixa (P1-1B2010-17), Instituto Universitario de Economía, Consolider-Ingenio 2010 and the Comunidad de Madrid (Excelencia).
} 
cost to the regulator. A common feature of the aforementioned studies is strategic interaction between agents leading to extraction levels which diverge from the economically efficient ones.

A different and rather neglected source of inefficiencies in water allocation relates to the fact that the scope of water management is defined within limited geographical areas whose extension depends on administrative divisions of land. This is especially relevant in the case of water transfers across regions and joint management of water from different resources. In recent years, apart from mixing water from different sources, recycling is also creating situations in which different water qualities have to be mixed. In such cases, the management of water from different sources affects the quality of water that each farm or household receives. Usually, the quality of water for household use must satisfy specific quality requirements. On the contrary, quality standards for farm use are much weaker. Thus, any authority supplying water to two different types of users who differ in their minimum acceptable qualities has an additional dimension to deal with: the optimal mix of qualities that should be supplied to users, implemented through the usual instrument of pricing by level of consumption.

In this paper we define a water market focusing on the novel feature of extraction from two different sources, leading to endogenous water quality ${ }^{1}$. We experimentally test the efficiency of two different market structures, labelled as duopoly and coordinated duopoly. Our results indicate that a more competitive market environment yields more efficient outcomes than those achieved in the collusive environment of the coordinated duopoly structure. A more general implication of this finding is that when the market mechanism is used to allocate water to its users the usual rules of thumb apply. That is, collusion among independent suppliers inefficiently restricts output and raises prices to consumers. Generally speaking, water market regulation should not be permissive towards anti-competitive practices like explicit agreements or coordination of actions by independent suppliers.

A second contribution of the paper regards the mechanism used in the determination of the market clearing price. This issue has received a lot of attention in the literature (see, for example, Varela-Ortega, 1998; Tsur and Dinar, 1997, etc.) which (also see BarShira et al. 2006) seems to converge towards an agreement on the fact that uniform pricing is weakly more efficient than block-rate pricing. Our method is a combination of block-rate pricing and uniform pricing in the following sense: Suppliers post block-rate bids to the market, but the market clears through a uniform price determined by the pricebid of the "last" block of each type of water consumed by the users. To implement this price formation mechanism, we programmed a "smart" agent representing the users. The agent allocates water among farmers and households in a way that maximizes consumer surplus conditional to the block-rate bids posted by the suppliers of the two different types

\footnotetext{
${ }^{1}$ Modifying the market clearing mechanism in Georgantzis et al. (2004) and considering a different set of alternatives from those in García-Gallego et al. (forthcoming).
} 
of water. Therefore, despite the independent profit-driven action of suppliers, our setup assumes and implements conditional collective optimality of actions on the demand side.

Finally, to our knowledge ours is the first paper in which a "confirmed strategies" protocol is used to implement a collusive environment in the framework of a dynamic experimental setting. Our findings show that, such a bargaining approach to coordination among independent suppliers is particularly efficient in inducing departures from the competitive outcome.

The paper is structured as follows. In Section 2 we describe the aquifer system. In Section 3 we discuss our experimental design. Section 4 discusses the experimental results. Section 5 concludes.

\section{THE AQUIFER SYSTEM}

There are two renewable stocks $S_{H}$ (high quality) and $S_{L}$ (low quality) from which water may be extracted. For the sake of simplicity, we assume that the recharge to the respective basin is deterministic and constant. The inflow to the respective basins is assumed to cease when the storage capacity of the aquifer is reached. That is, once the maximum storable stock is reached, extra water inflow is lost. The return flow of consumed water is assumed to be negligible. Thus, changes in the stocks are exclusively due to extraction and recharge. Extraction costs are supposed to be twice differentiable functions of quantity and stock size. First derivatives are assumed to be, respectively, positive and negative, whereas second derivatives are positive.

We allow for the possibility that the water resources differ in qualities. Quality of water in an aquifer may be lower due to marine intrusion, or due to infiltration of fertilizer from agriculture. Let the qualities be denoted respectively by $Q_{H}$ and $Q_{L}$, where $Q_{H}>Q_{L}>0$. The two qualities are assumed to be constant over time. However, any intermediate quality may be supplied to the consumers as a result of mixing water from the two sources. Note that, usually, quality choice is studied in the context of static product differentiation models. In these models, product quality is chosen in a way which takes into account the competition-reducing effect of product differentiation. Thus, quality choice determines the fierceness of price competition. Here, the causality is reversed. Final product quality is the result of price setting behaviour. Thus, strategic interaction determines the final quality which is unique and not directly controlled by any single agent.

Mixing quantities $\mathrm{K}_{H}$ and $\mathrm{K}_{\mathrm{L}}$ of the two qualities results in water whose quality is given by the weighted average:

$$
Q_{M}\left(K_{H}, K_{L}, Q_{H}, Q_{L}\right)=\frac{K_{H} Q_{H}+K_{L} Q_{L}}{K_{H}+K_{L}}
$$

Resource flow between the sources and the consumers is coordinated by a pair of 
knots, which centralize the mixing process at the consumer's location. Figure 1 represents the distribution scheme described above.

Suppose that the behaviour of the consumers can be aggregated under one of two types: i) households $(h)$, and ii) farmers $(F)$. Consumers differ in their respective preferences regarding the quality of water. Both types prefer a higher quality and quantity of the water to a lower one. Households consume water whose quality weakly exceeds a minimum standard. If mixed quality does not satisfy this condition, it will be subject to purification.

Quality of potable water should weakly exceed the constant minimum quality standard $Q_{\min }$, where $Q_{H}>Q_{\min }>Q_{L}$. Mixed water of quality $Q_{M}$ may, or may not, satisfy the minimum quality standard. This depends on the quantities and the qualities which are mixed. Quality may be improved at a cost. This cost is an increasing function of the difference between the quality before and after depuration. Moreover, a given improvement $\Delta Q$ of a lower quality is less costly than the same improvement performed on a higher quality. Let the initial quality subject to purification be $Q_{0}$. The purification cost, denoted by $C_{\Delta Q}\left(K, \Delta Q, Q_{0}\right)$, for a certain water quality $Q_{0}$ and quantity $K=K_{H}+K_{L}$ requiring a quality improvement $\Delta Q$, is assumed to satisfy the following conditions:

$$
\frac{\partial C_{\Delta Q}}{\partial K}>0, \frac{\partial^{2} C_{\Delta Q}}{\partial K^{2}}>0, \frac{\partial C_{\Delta Q}}{\partial \Delta Q}>0, \frac{\partial^{2} C_{\Delta Q}}{\partial(\Delta Q)^{2}}>0,\left.\frac{\partial C_{\Delta Q}}{\partial Q_{0}}\right|_{\Delta Q}>0,\left.\frac{\partial^{2} C_{\Delta Q}}{\partial Q_{0}^{2}}\right|_{\Delta Q}>0
$$

Figure 1.

The pipeline network

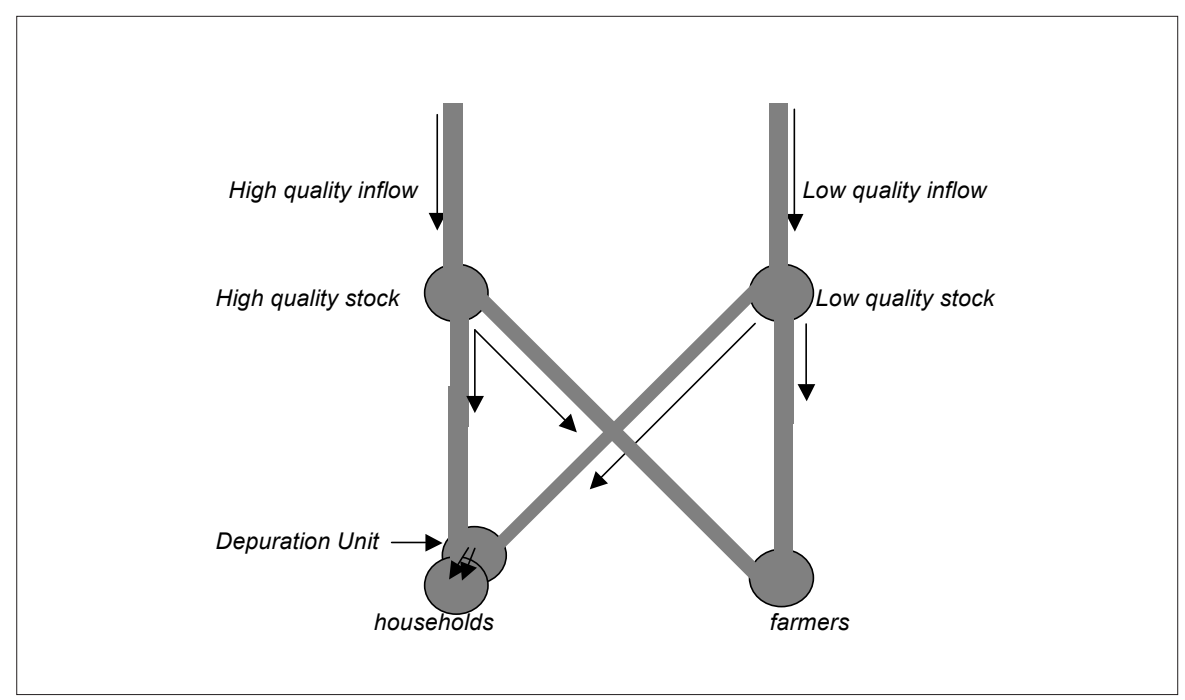


The purification procedure is assumed to be costly enough such that it is not profitable to improve quality above the minimum standard. Hence, the quality consumed by households is the maximum between the minimum, and the mixed, quality. Thus, $Q_{0}=Q_{M}$ and,

$$
\Delta Q= \begin{cases}Q_{\min }-Q_{M}, & \text { if } Q_{\min }>Q_{M} \\ 0 & , \text { if } Q_{\min } \leq Q_{M}\end{cases}
$$

Our assumptions concerning consumer utility are qualitatively similar to those in Williams et al. (1986) on multiple commodities which are interdependent in consumption. Two features, which are rather specific to the dynamics of water, are added to the structure: first, buyers are restricted to purchase up to a certain amount of each type of water. Second, a constant inflow (recharge) in each period maintains the stock of water in the basins of each producer. In fact, following a standard formulation of similar groundwater extraction problems, a lower stock implies a higher extraction cost. Thus, each period's marginal cost and past levels of extraction are positively correlated.

Let the households take the purification cost into account in their utility function. Further, assume utility functions for the respective consumer-types,

$$
\begin{aligned}
& U_{h}=U_{h}\left(K_{h}, Q_{M h}\right) \text { and } U_{F}=U_{F}\left(K_{P} Q_{M F}\right) \\
& \text { where } K_{h}=K_{H h}+K_{L h} \text {, and } K_{F}=K_{H F}+K_{L F}
\end{aligned}
$$

to be twice differentiable with respect to the quantity and the mixed quality. A farmers' utility is increasing in both arguments. While depending on the purification cost function, the utility function of households might be increasing in the quantity of low quality only up to a certain limit². From twice differentiability of the utility functions it follows that the sum of the functions is twice differentiable, too. The indirect social welfare function $V\left(K_{H}, K_{L}\right)$, which maximizes consumer surplus for a given quantity of water, can be obtained as a solution to the following problem:

$V\left(K_{H}, K_{L}\right)=\max _{K_{\text {Hhh }}, K_{L h h}} U_{h}\left(K_{H h}, K_{L h}, Q_{M h} ; K_{H}, K_{L}\right)+U_{F}\left(K_{H F}, K_{L F}, Q_{M F} ; K_{H}, K_{L}\right)$

s.t.

(i) $K_{H}=K_{H h}+K_{H F}$

(ii) $K_{L}=K_{L h}+K_{L F}$

(iii) $Q_{M h}=\frac{Q_{H} K_{H h}+Q_{L} K_{L h}}{K_{H h}+K_{L h}}$

(iv) $Q_{M F}=\frac{Q_{H} K_{H F}+Q_{L} K_{L F}}{K_{H F}+K_{L F}}$

${ }^{2}$ In fact, it will be increasing if mixed quality weakly exceeds the minimum quality standard. 
As a benchmark for our experimental results, we are interested in the socially optimal solution of water supply. Given the assumptions above, we formulate the program that maximizes social welfare. ${ }^{3}$ Without loss of generality, suppose that initially the resource stocks are in the natural hydrological equilibrium, i.e. at the upper bound of the storage capacity. Let $\left(a_{H}, a_{L}\right)$ denote recharges of the two water qualities of water, and $t_{0}$ the starting time of extraction. Assume that the social rate of discount is $\delta$. Thus, the intertemporal social objective function is formulated as follows:

$$
\max _{K_{H t}, K_{L t}} \int_{t_{0}}^{\infty} e^{-\delta t}\left[V\left(K_{H t}, K_{L t}\right)-C_{H t}\left(K_{H t}, S_{H t}\right)-C_{L t}\left(K_{L t}, S_{L t}\right)\right] d t
$$

s.t.

(i) $\frac{d S_{H t}}{d t}=\left\{\begin{array}{cc}-K_{H t}+a_{H}, & \text { if } S_{H}<S_{H}^{\max } \\ 0, & \text { otherwise }\end{array}\right.$
(ii) $\frac{d S_{L t}}{d t}=\left\{\begin{array}{cc}-K_{L t}+a_{L}, & \text { if } S_{L}<S_{L}^{\max } \\ 0, & \text { otherwise }\end{array}\right.$

(iii) $S_{H t_{0}}=S_{H}^{\max }$

(iv) $S_{L t_{0}}=S_{L}^{\max }$

Observe that in the case of a dynamic duopoly game played by water supply firms strategies aim at":

$$
\max _{K_{H t}} \int_{t_{0}}^{\infty} e^{-\delta t}\left[R_{H}\left(K_{H t}\right)-C_{H t}\left(K_{H t}, S_{H t}\right)\right] d t
$$

s.t.

(i) $\frac{d S_{H t}}{d t}=\left\{\begin{array}{cc}-K_{H t}+a_{H}, & \text { if } S_{H}<S_{H}^{\max } \\ 0, & \text { otherwise }\end{array}\right.$

(ii) $S_{H t_{o}}=S_{H}^{\max }$

${ }^{3}$ This problem is solvable by means of optimal control theory, where the stocks are the states and the quantities the control variables.

${ }_{4} R_{H}\left(K_{H}\right)$ and $R_{L}\left(K_{L}\right)$ represent, respectively, the reserve price for high and low quality suppliers. 
for the supplier of high quality water, and,

$$
\begin{aligned}
& \max _{K_{L t}} \int_{t_{0}}^{\infty} e^{-\delta t}\left[R_{L}\left(K_{L t}\right)-C_{L t}\left(K_{L t}, S_{L t}\right)\right] d t \\
& \text { s.t. } \\
& \text { (i) } \frac{d S_{L t}}{d t}=\left\{\begin{array}{cc}
-K_{L t}+a_{H}, & \text { if } S_{L}<S_{L}^{\max } \\
0, & \text { otherwise }
\end{array}\right. \\
& \text { (ii) } S_{L t_{o}}=S_{L}^{\max }
\end{aligned}
$$

for the low quality supplier, respectively, which in comparison with the social welfare static maximization shows that private managers do not account for each one's water quality effect on the social value generated by the other quality. Following standard results from dynamic duopoly games, it can be shown that private water suppliers will reduce output with respect to the social optimum described above.

By means of the resulting current value Hamiltonian and Pontryagin's maximum principle (assuming an interior solution) the two following conditions have to be satisfied in the hydro-economic equilibrium:

$$
\begin{aligned}
& \left.\frac{\partial V\left(K_{H}, K_{L}\right)}{\partial K_{H}}\right|_{\left(K_{H}, K_{L}\right)=\left(a_{H}, a_{L}\right)}=\left.\frac{\partial C_{H}\left(S_{H}, K_{H}\right)}{\partial K_{H}}\right|_{\left(K_{H}, K_{L}\right)=\left(a_{H}, a_{L}\right)}-\left.\frac{1}{\delta} \frac{\partial C_{H}\left(S_{H}, K_{H}\right)}{\partial S_{H}}\right|_{K_{H}=a_{H}} \\
& \left.\frac{\partial V\left(K_{H}, K_{L}\right)}{\partial K_{L}}\right|_{\left(K_{H}, K_{L}\right)=\left(a_{H}, a_{L}\right)}=\left.\frac{\partial C_{L}\left(S_{L}, K_{L}\right)}{\partial K_{L}}\right|_{\left(K_{H}, K_{L}\right)=\left(a_{H}, a_{L}\right)}-\left.\frac{1}{\delta} \frac{\partial C_{L}\left(S_{L}, K_{L}\right)}{\partial S_{L}}\right|_{K_{L}=a_{L}}
\end{aligned}
$$

The conditions in (7) simultaneously determine the steady-state standing-stocks of $S_{H}$ and $S_{L}$. They basically state that, in the long-run, the marginal social utility, which embodies the respective resource price in the economy, should equal the social costs of extraction represented on the right hand side. ${ }^{5}$

However, a benevolent, infinitely living planner should equally care for the welfare of both present and future generations. This is the case actually implemented in our experiments because subject rewards depended equally on profits earned in earlier and later periods. In fact, a planner who is equally interested in present and future welfare will maximize efficiency in each period and will not sacrifice future efficiency in favour

\footnotetext{
${ }^{5}$ In each condition, the first term (positive) represents the marginal cost which results from extracting a quantity $K_{H}\left(K_{L}\right)$ from the water stock $S_{H}\left(S_{L}\right)$. The second term reflects the shadow price of the resource.
} 
of higher present extraction as implied by (7). Thus, formally, we are interested in the special case of $\delta=0$, the conditions above then become:

$$
\begin{aligned}
& \left.\frac{\partial C_{H}\left(S_{H}, K_{H}\right)}{\partial S_{H}}\right|_{K_{H} \leq a_{H}}=0 \\
& \left.\frac{\partial C_{L}\left(S_{L}, K_{L}\right)}{\partial S_{L}}\right|_{K_{L} \leq a_{L}}=0
\end{aligned}
$$

Given our formulation, the conditions in (8) imply that in order to implement the firstbest solution a social planner should never let the stock levels fall to the point where extraction costs become positive. This solution will, in general, differ from the one observed under independent private-profit driven management of the two resources. As a result, a private duopoly with independently acting suppliers will have incentives to extract less than predicted by the socially optimal solution described above. The collusive duopoly will further deviate from the socially optimal solution on the same direction as the standard duopolistic market towards the monopoly solution. Specifically, equilibrium for the non-cooperative duopolistic management structure is characterized by the condition:

$$
\begin{aligned}
& \left.\frac{\partial R_{H}\left(K_{H}, K_{L}\right)}{\partial K_{H}}\right|_{\left(K_{H}, K_{L}\right)=\left(a_{H}, a_{L}\right)}=\left.\frac{\partial C_{H}\left(S_{H}, K_{H}\right)}{\partial K_{H}}\right|_{\left(K_{H}, K_{L}\right)=\left(a_{H}, a_{L}\right)}-\left.\frac{1}{\delta} \frac{\partial C_{H}\left(S_{H}, K_{H}\right)}{\partial S_{H}}\right|_{K_{H}=a_{H}} \\
& \left.\frac{\partial R_{L}\left(K_{H}, K_{L}\right)}{\partial K_{L}}\right|_{\left(K_{H}, K_{L}\right)=\left(a_{H}, a_{L}\right)}=\left.\frac{\partial C_{L}\left(S_{L}, K_{L}\right)}{\partial K_{L}}\right|_{\left(K_{H}, K_{L}\right)=\left(a_{H}, a_{L}\right)}-\left.\frac{1}{\delta} \frac{\partial C_{L}\left(S_{L}, K_{L}\right)}{\partial S_{L}}\right|_{K_{L}=a_{L}}
\end{aligned}
$$

where, $R_{H}$ and $R_{b}$ denote the two competing entities' revenues, respectively. This resembles the standard duopoly case. The left hand side in (9) fails to account for the negative externality of each type of water on the profitability of the other. That is, while the monopolist accounts for the effect of selling an extra unit of high quality water on the market price of low quality (and vice-versa), duopolists do not internalize the horizontal externality. For $\delta=0$, the conditions in (9) become:

$$
\begin{aligned}
& \left.\frac{\partial C_{H}\left(S_{H}, K_{H}\right)}{\partial S_{H}}\right|_{K_{H}=a_{H}}=0 \\
& \left.\frac{\partial C_{L}\left(S_{L}, K_{L}\right)}{\partial S_{L}}\right|_{K_{L}=a_{L}}=0
\end{aligned}
$$




\section{EXPERIMENTAL DESIGN}

Our experimental setup aims at studying how different levels of competitiveness affect the efficiency of a duopolistic market supplying water to a heterogeneous population of consumers. Two different levels of competitiveness are implemented. A standard duopolistic structure is compared with a collusive environment resulting from the adoption of a confirmed strategies protocol, which is explained in detail below.

As explained in the underlying theoretical framework, the quality of water reaching the final consumer is not directly controlled by any one of the agents in the market. Instead, it is the result of bidding behaviour by the two agents controlling the resources. Their only strategic variable is the minimum price at which they are willing to sell each unit-block of each type of water to the consumer.

We use the model described in the previous section with the following values for the parameters:

(i) Recharge: $\left(a_{H^{\prime}} a_{L}\right)=(3,3)$

(ii) Initial and maximum stock sizes $\left(S_{H}, S_{L}\right)=(20,20)$

(iii) Water qualities: $\left(Q_{H}, Q_{L}\right)=(5,1)$

(iv) Minimum quality standard demanded by the household: $Q_{\min }=3$

The specific utility and cost functions used are provided in Appendix A. To avoid subjects making uncontrolled guesses concerning the end of the session, a deterministic end game horizon was used (a total of 50 periods), which was known by subjects from the beginning of the experiment. ${ }^{6}$

Each subject knew the type of water they would have to manage over the entire session. Furthermore, they were conscious about a generic preference by consumers for one good (high quality) over the other. Moreover, they knew that each water quality is a demand substitute (though not perfect) of the other and that their extraction cost structures were identical to each other's. A simulator (made available to them on their decision screen) informed them on the hypothetical costs and gains they would make if they sold all the units of each product for which they were currently submitting post bids. They knew that the actual number of units they sold would be known only after they had posted their period bids and that the (automated) demand's reaction to these bids was announced to them on the feedback screen.

In a two-treatment design, we analyse two different scenarios concerning the management of the two sources of water. In the first treatment, labelled as Private Duopoly $(P D)$, subjects act as one of the two suppliers who act independently from each other (using a different PC each), posting simultaneously their pricing schedules in the form

\footnotetext{
${ }^{6}$ Given the complex nature of the problem faced by our subjects, we chose a 50-period horizon in order to allow for sufficient learning to be acquired during the session.
} 
of 5 minimum prices at which they are willing to sell each one of a maximum of 5 units they may supply to the market. Subjects were told that offer bids had to exceed weakly the cost of the corresponding unit, and offers of subsequent units would have to be nondecreasing. Subjects were rewarded according to their accumulated profits over the 50 periods of the experiment. Thus, the two sources of water are separately managed by two different subjects representing two profit maximizing firms.

In the second treatment, labelled as Coordinated Duopoly (CD), the two resources are also managed by different subjects. However, each pair of "competing" subjects sits in front of the same terminal. They have to post bids exactly in the same way as in the standard duopoly treatment, with the only difference that each subject can observe the bids announced by the rival supplier for the following period. Strategies are not submitted unless both subjects agree to press the "OK" button. This happens after having observed iteratively the strategies announced by the other supplier and correcting as many times as necessary their own price bids. To our knowledge, this protocol is the first experimental implementation of a duopolistic game with confirmed strategies. In the Appendix, we provide an example of the anti-competitive effects of confirmed-strategy bargaining on the equilibrium of a prisoners' dilemma game. Our design implicitly assumes that this result would carry over to a dynamic and complex duopolistic setup like the one studied here. However, there are no theoretical results available on this intuition.

Furthermore, our experiment is the first to use the confirmed-strategy mechanism as a means of implementing an anti-competitive environment in the lab instead of the usual oral or on-line communication protocols. As we will see in the following section, communication and agreement on the timing of decision submission and the possibility of iterated inspection of the "competitor's" strategy before jointly pressing the "OK" button render this setup highly collusive. However, individual actions and incentives remained uncoordinated and no side payments were feasible.

Given each bidding schedule posted by the entities selling water, consumer surplus maximization determines the quantity of each quality consumed and, thus, the average quality of water. This is a rather complex problem especially due to the uncoordinated action of sellers, but also due to the dynamic nature of the market. The method used to determine the market clearing price is a combination of block-rate and uniform pricing in the following sense: Suppliers post block-rate bids to the market, but the market clears through a uniform price determined by the price-bid of the "last" block of each type of water consumed by the users. To implement this price formation mechanism, we programmed a "smart" agent representing the users. The agent allocates water among farmers and households in a way that maximizes consumer surplus conditional to the block-rate bids posted by the suppliers of the two different types of water. Therefore, despite the independent profit-driven action of suppliers, our setup assumes and implements conditional collective optimality of actions on behalf of the consumers.

The resulting feedback from the demand model is difficult to interpret by the subjects or "linearize" in any sense. Unit extraction costs increase in "steps" as the level of stock of each water quality decreases. Therefore, in each period costs depend on extraction in previous periods. 
A history window displays all past outcomes regarding each supplier's own decisions, i.e. quantities, payoffs and market prices. Each subject also receives the clearing price at which the "other" water quality was sold.

The experiment was organized using the software Hydromanagement which was developed in Java for the Laboratorio de Economía Experimental (LEE) of the Universitat Jaume I of Castellón (Spain), where all sessions were run. Five 20-subject sessions (a total of $5 \times 10=50$ duopolies) were run under treatment $P D$ and two 40 -subject sessions (a total of $2 \times 20=40$ duopolies) were run under treatment $C D$. A number of learning rounds (not reported here) were run at the beginning of each session. In order for "social learning" to be avoided, sessions from different treatments were run in a random order. Sessions lasted an average of 80 minutes each. In all treatments, the subjects' monetary rewards were proportional to their accumulated profits over the 50 periods. Average per subject earnings were slightly below $25 €$.

\section{RESULTS}

The results are presented in figures 2 to 7 . Comparison of figures 2 and 3 indicates that the collusive duopoly has restricted the output (reflected on higher stocks) of high quality water more than the standard duopoly. Whereas, the standard duopolistic structure

Figure2.

Private vs. Coordinated Duopoly: Evolution of average stocks (low quality)

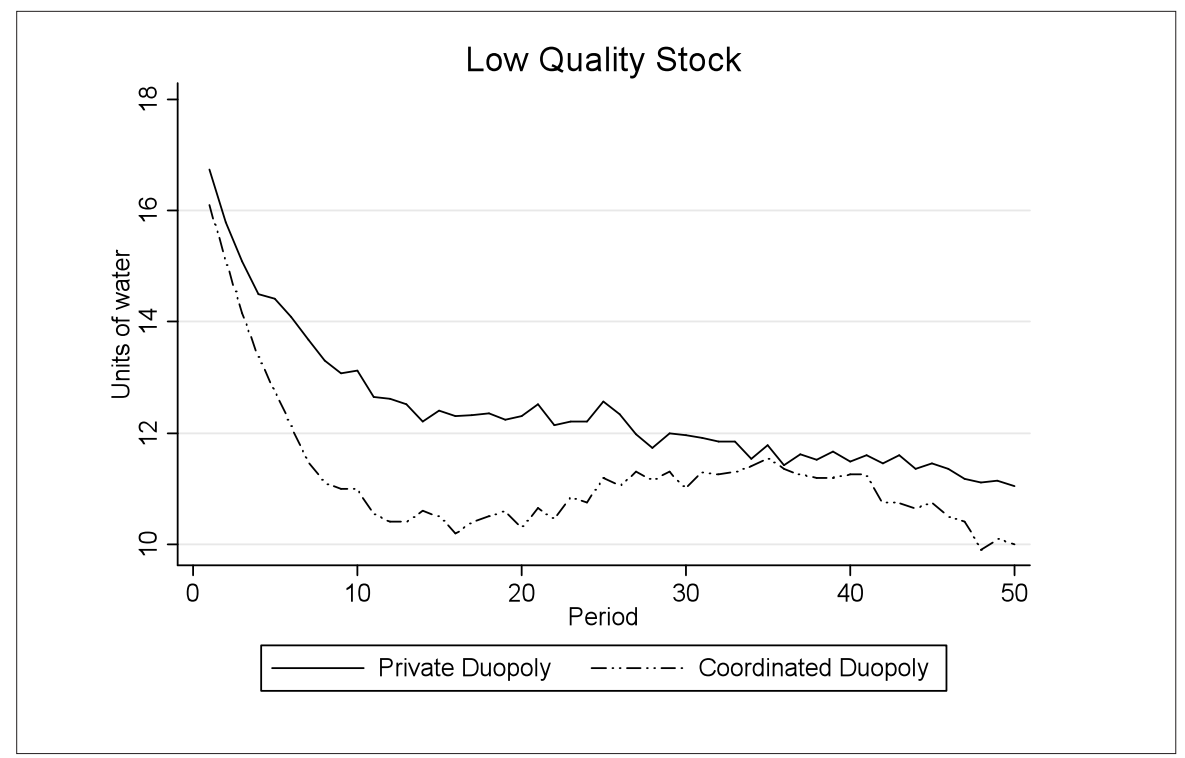


Figure 3.

Duopoly vs. Coordinated Duopoly: Evolution of average stocks (high quality)

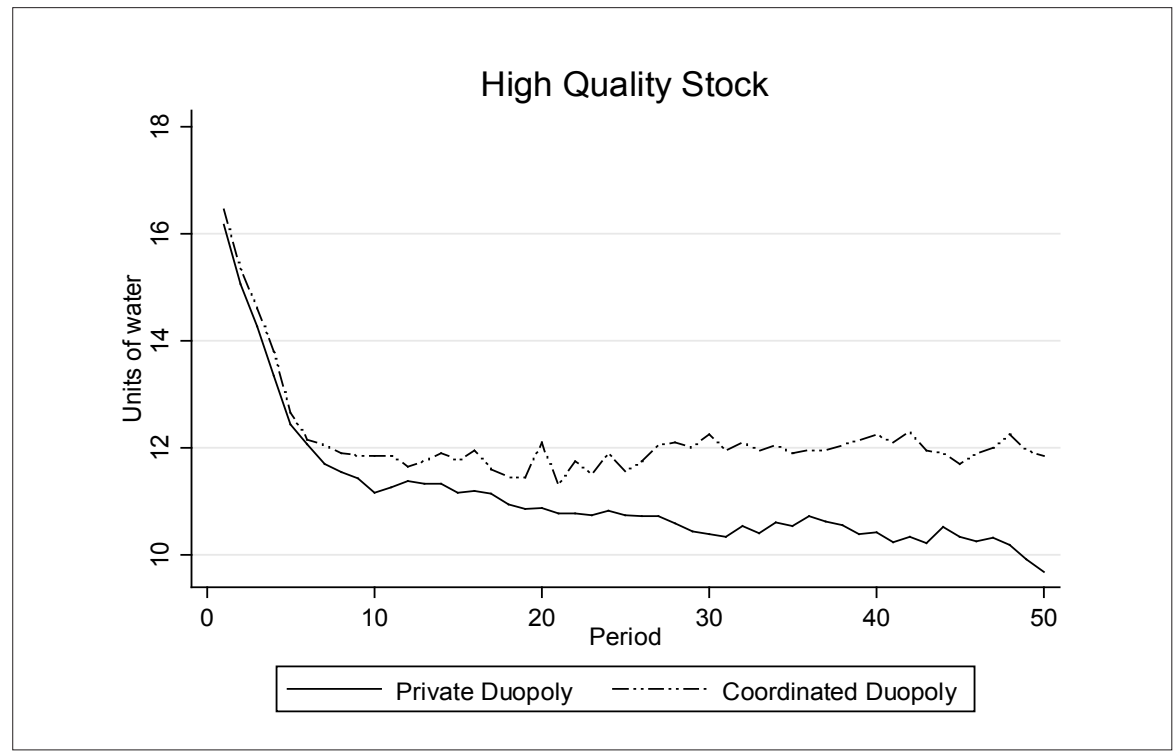

Table 1.

Descriptive statistics from the last 30 periods

\begin{tabular}{|l|r|r|r|r|r|r|r|r|}
\hline & \multicolumn{2}{|c|}{ Low Q. Stock } & \multicolumn{2}{c|}{ High Q. Stock } & \multicolumn{2}{c|}{ Low Q. Quantity } & \multicolumn{2}{c|}{ High Q. Quantity } \\
\hline & \multicolumn{1}{|c|}{ PD } & \multicolumn{1}{c|}{ CD } & \multicolumn{1}{c|}{ PD } & CD & PD & CD & PD & CD \\
\hline Average & 12.4 & 11.2 & 11.1 & 12.2 & 3.0 & 3.0 & 3.0 & 2.9 \\
\hline Std. D. & 1.2 & 1.2 & 1.2 & 0.9 & 0.2 & 0.3 & 0.3 & 0.3 \\
\hline Av. 20-50 & 11.7 & 10.9 & 10.5 & 12.0 & 2.9 & 2.9 & 2.9 & 2.8 \\
\hline St.D.20-50 & 0.4 & 0.4 & 0.3 & 0.2 & 0.2 & 0.2 & 0.1 & 0.3 \\
\hline
\end{tabular}

\begin{tabular}{|l|c|c|c|c|c|c|}
\hline & \multicolumn{2}{|c|}{ Low Quality Price } & \multicolumn{2}{c|}{ High Quality Price } & \multicolumn{2}{c|}{ Av. Quality/Price } \\
\hline & PD & CD & PD & CD & PD & CD \\
\hline Average & 69.8 & 96.7 & 75.7 & 98.6 & 0.04 & 0.04 \\
\hline Std. D. & 5.2 & 12.8 & 8.1 & 11.7 & 0.01 & 0.01 \\
\hline Av. 20-50 & 72.2 & 102.9 & 80.0 & 103.8 & 0.04 & 0.03 \\
\hline St.D.20-50 & 3.6 & 4.4 & 5.3 & 4.3 & 0.00 & 0.00 \\
\hline
\end{tabular}

PD: Private Duopoly; CD: Coordinated Duopoly. 
Figure 4.

Duopoly vs. Coordinated Duopoly: Evolution of prices (low quality water)

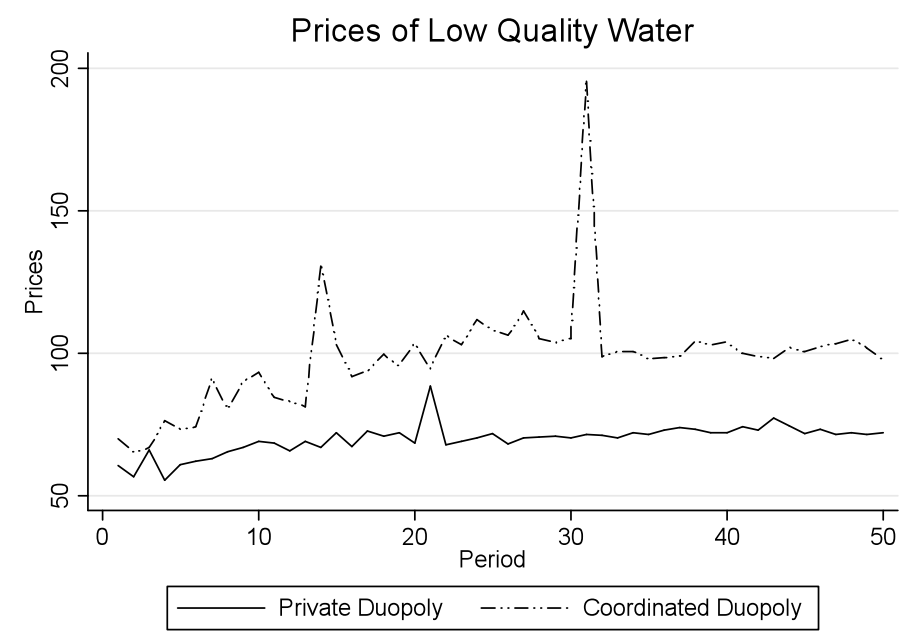

Figure 5.

Duopoly vs. Coordinated Duopoly: Evolution of prices (high quality water)

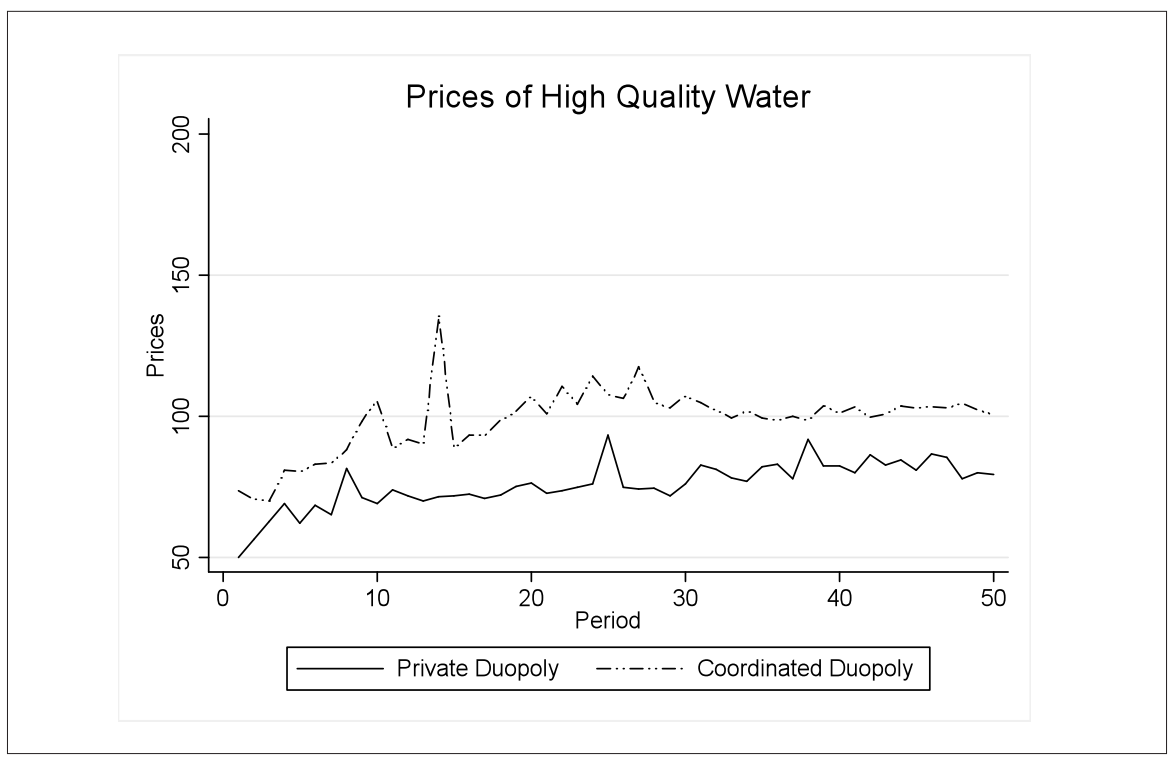


has lead to lower output (higher stocks) of low quality water than is done in the case of coordinated duopolies. Figures 4 and 5 indicate that prices for both types of water have been significantly higher in the case of coordinated duopolies, which confirms the anti-competitive nature of this type of market. In table 1 we present some descriptive statistics.

Figures 6 and 7 show that since the early periods experimental subjects sell as many units of each resource as the inflow provides. They thus closely follow the temporal pattern dictated by the hydrological equilibrium of the system, according to which input should equal output for the stocks to remain stable across periods. Obviously, volatility is a non- negligible problem of water management under both market mechanisms.

The quantities traded in each period are on average not significantly different from the socially optimal levels which coincide with the hydrological equilibrium of the system described by the rule of equality between inflow and consumption.

Figure 8 contains the evolution of average quality-to-price ratios defined by the magnitude:

$$
\bar{Q} / \bar{P} \text {, where: } \bar{Q}=\frac{K_{H} \cdot Q_{H}+K_{L} \cdot Q_{L}}{K_{H}+K_{L}} \text { and } \bar{P}=\frac{K_{H} \cdot P_{H}+K_{L} \cdot P_{L}}{K_{H}+K_{L}}
$$

Although most of the differences are not significant, the coordinated duopoly treatment has yielded systematically lower quality-to-price ratios.

Figure 6.

Duopoly vs. Coordinated Duopoly: Evolution of quantities (low quality)

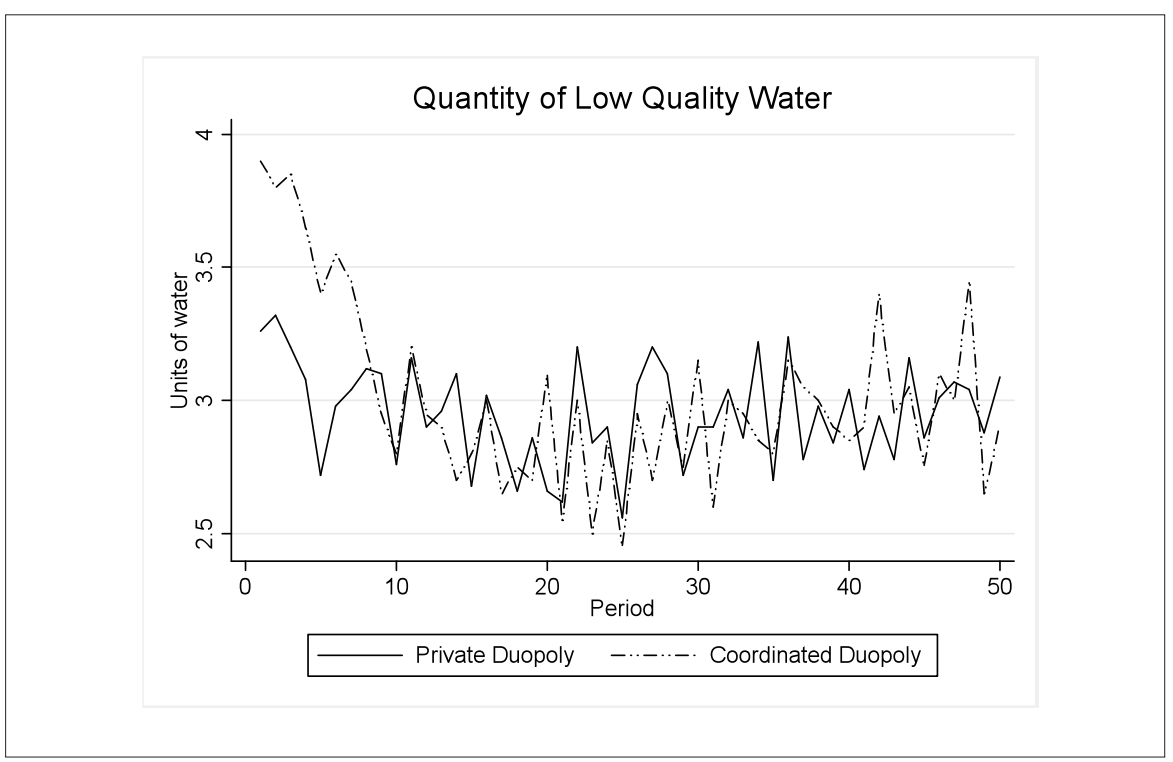


Figure 7.

Duopoly vs. Coordinated Duopoly: Evolution of quantities (low quality)

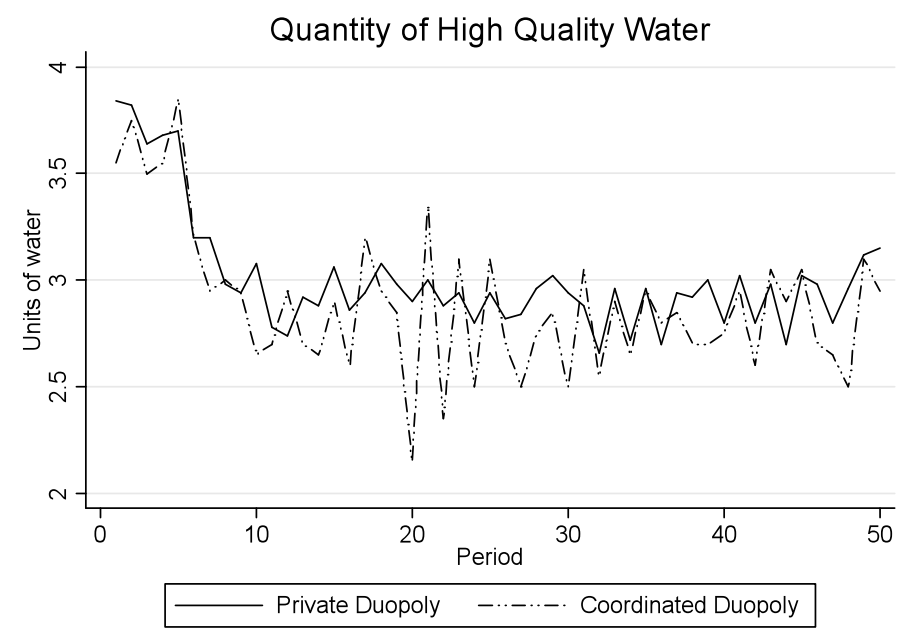

Figure 8.

Duopoly vs. Coordinated Duopoly: Evolution of Quality to Price Ratio

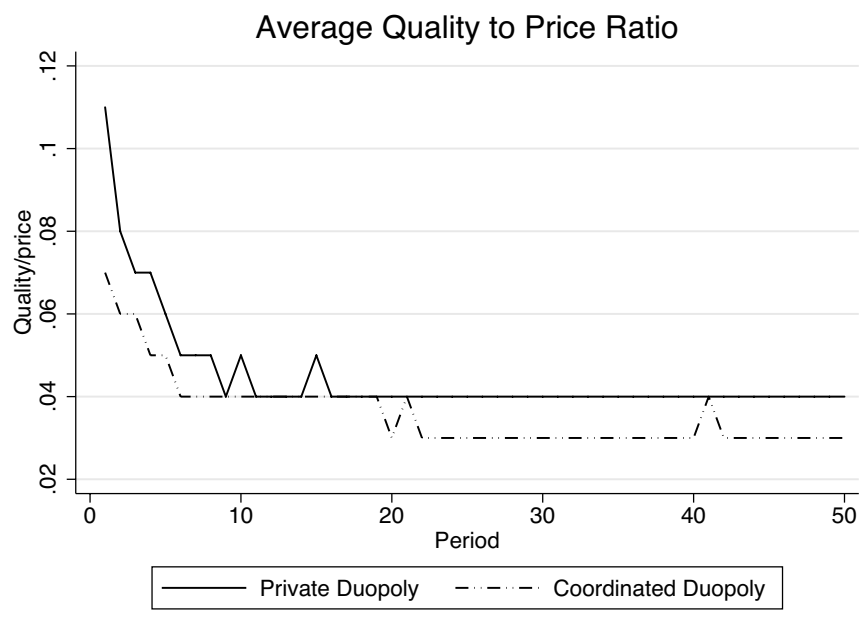


Summarizing the results reported above, we can say that in our framework, collusive (i.e. coordinated) duopolistic water markets are less efficient than duopolistic markets with independently acting water suppliers. High stock level and prices are observed for both the cases, with the coordinated duopoly showing relatively lower stock level, while more moderate inefficiencies are reflected on lower quality-to-price ratios.

\section{Conclusions}

Contrary to previous experimental studies on resource markets, our setup assumes extraction from separate pools and competition in the distribution stage. This structure is inspired by the problem, of growing importance in many countries, concerning the desirability of water management decentralization through the use of market mechanisms.

A general finding is that prices are useful in allocating water resources. Furthermore, private management could suffer from an increased concern not to overexploit the resources. However, more competitive markets yield higher levels of market efficiency and moderately higher quality to price ratios.

Whether the complexity of the problem and the resulting feedback induce a persistent learning shortcoming or not is not answered by our results so far. Therefore, an interesting extension of the experiments presented here would be to allow for longer sessions, or running future sessions with experienced subjects.

\section{REFERENCES}

Attanasi, G., Garcia-Gallego, A., Georgantzís, N. and A. Montesano. 2011. "Non-cooperative games with chained confirmed proposals." Pp. 19-32 in Contributions to Game Theory and Management edited by L.A. Petrosjan and N.A. Zenkevitch Vol. IV. Forthcoming.

Bar-Shira, Z., Finkelshtain, I. and A. Simhon. 2006. "Block-rate versus uniform water pricing in agriculture: An empirical analysis." American Journal of Agricultural Economics 88:986-999.

García-Gallego, A., Georgantzis, N., Hernán-González R. and P. Kujal (in press) "How do markets manage water resources? An experiment." Forthcoming at the Enviromental and Resource Economics.

Gardner, R., Moore, M.R. and J.M. Walker. 1997. "Governing a groundwater commons: A strategic and laboratory analysis of western law." Economic Inquiry 35:218-234.

Georgantzis, N., García-Gallego, A., Fatas, E., Neugebauer, T. and P. Kujal. 2004. "Mixture and distribution of different water qualities: An experiment on vertical structure in a complex market." Cuadernos de Economía 27:95-138.

Gordon, H.S. 1954. "The economic theory of a common property resource: The fishery." Journal of Political Economy 62:124-142. 
Mason, C.F. and O.R. Phillips. 1997. "Mitigating the tragedy of the commons through cooperation: An experimental evaluation." Journal of Environmental Economics and Management 34:148-172.

McCabe, K.A, Rassenti, S.J. and V.L. Smith. 1989. "Designing 'smart' computer assisted markets in an experimental auction for gas networks." European Journal of Political Economy 5:259-283.

McCabe, K.A., Rassenti, S.J. and V.L. Smith. 1991. "Smart computer assisted markets." Science 254:534-38.

Moench, M. 1992. "Chasing the water table: equity and sustainability in groundwater management." Economic and Political Weekly 27 (nos. 51-52): A171-A177.

Murphy, J.J., Dinar, A., Howitt, R.E., Rassenti, S.J., and V.L. Smith. 2000. "The design of smart water market institutions using laboratory experiments." Environmental and Resource Economics 17:375-394.

Tsur, Y., and A. Dinar. 1997. "The relative efficiency and implementation costs of alternative methods for pricing irrigation water." World Bank Economic Review 11:243-262.

Varela-Ortega, C., J.M. Sumpsi, A. Garrido, M. Blanco, and E. Iglesias. 1998. "Water pricing policies, public decision making and farmers' response: implications for water policy." Agricultural Economics 19:193-202.

Walker, J.M., Gardner, R. and E. Ostrom. 1990. "Rent dissipation in limited access common pool resource environments: experimental evidence." Journal of Environmental Economics and Management 19:203-211.

Walker, J.M. and R. Gardner. 1992. "Probabilistic destruction of Common-pool Resources: experimental evidence." The Economic Journal 102:1149-1161.

Williams, A., Smith, V.L. and J. O. Ledyard. 1986. "Simultaneous trading in two competitive markets: An experimental examination." Technical report, Indiana University, Bloomington.

Aurora García-Gallego is Full Professor at the Economics Department of the University Jaume I (Castellón, Spain). She is co-director and researcher of the Laboratorio de Economía Experimental (LEE) and founding member of the spin-off firm Experimentia Consulting. Her research interests are mainly experimental and behavioural economics. Her work has been published in journals like IJIO, Regional Science and Urban Economics, JEBO, JEMS, Theory and Decision, Environmental and Resource Economics, Ecological Economics or Economics Letters.

Nikolaos Georgantzis is Professor of Economic Theory and Experimental Economics at the Universitat Jaume I (Castellón-Spain), where he founded the Laboratorio de Economia Experimental (LEE). Since 2008, he holds a Research Chair financed by the Junta de Andalucía at the Universidad de Granada, where he founded the experimental economics laboratory EGEO. His research interests include experimental economics and industrial organization.

Roberto Hernán-GonzÁlez is Assistant Professor at the Department of Economic Theory and Economic History of the University of Granada (Spain), and Visiting Research Associate Professor at the Economic Science Institute of Chapman University, USA. 
Praveen Kujal is the founding member and co-director of the Laboratory for Experimental Economics (LEE-UC3M, 2010) of the Universidad Carlos III. He has been the associate editor of Emerging Markets Review and is research affiliate of the Economic Science Institute, Chapman University, USA. He has published his research in economic outlets such as The Economic Journal, Journal of International Economics, Handbook of Results in Experimental Economics, International Journal of Industrial Organization, Research Policy or the Journal of Economic Behavior and Organization.

RECEIVED: 20 September 2011

ACCEPTED: 7 January 2012 


\section{APPENDIX}

\section{Mathematical model}

We provide here the specific mathematical expressions used here to implement the model outlined in the main text. The household's utility is given by the following function:

$$
U^{h}\left(K_{H h}, K_{L h}, Q_{M h}\right)=205 \cdot \ln \left(1+\left(\max \left\{Q_{\min }, Q_{M h}\right\}+\left(K_{L h}+K_{H h}\right)\right) \cdot\left(K_{L h}+K_{H h}\right)-C_{\Delta Q_{h}}\right)
$$

where the last term in brackets denotes the purification costs:

$$
C_{\Delta Q_{h}}\left(K_{H h}, K_{L h}, Q_{M h}\right)=\left\{\begin{array}{l}
\frac{\Delta Q_{h}^{2}}{3}\left(Q_{M h}^{2}+\left(K_{H h}+K_{L h}\right)^{2}\right), \text { if } Q_{\text {min }}>Q_{M h} \\
0, \quad \text { otherwise }
\end{array}\right.
$$

The farmer's utility function is as follows:

$$
U^{F}\left(K_{H F}, K_{L F}, Q_{M F}\right)=170 \cdot \ln \left[1+0.5 \cdot\left(Q_{M F}+3 \cdot\left(K_{L F}+K_{H F}\right)\right) \cdot\left(K_{L F}+K_{H F}\right)\right]
$$

Resource is $(i=H, L)$ extraction costs of $K_{i}$ units is denoted by $C_{i}\left(K_{i}\right)$, containing information on the cost of extracting one unit of the resource from a given stock level. For the discrete case implemented here, this information is summarized in the Table 3 of extraction costs, below. Given the quantity restriction of 5 units and the discrete quantity space allowed, the following utility levels in table 2 were assigned to the household $(h)$ and the farmer $(F)$ populations:

\begin{tabular}{|c|c|c|c|c|c|c|}
\hline hous. Low & 0 & 1 & 2 & 3 & 4 & 5 \\
\hline \multirow[t]{6}{*}{ High } & 0 & 174 & 301 & 356 & 378 & 378 \\
\hline & 399 & 492 & 579 & 637 & 679 & 711 \\
\hline & 555 & 624 & 690 & 753 & 797 & 832 \\
\hline & 660 & 717 & 771 & 822 & 869 & 906 \\
\hline & 740 & 789 & 836 & 880 & 920 & 959 \\
\hline & 806 & 849 & 890 & 929 & 965 & 999 \\
\hline
\end{tabular}

Table 2.

\begin{tabular}{|c|c|c|c|c|c|c|c|}
\hline \multicolumn{2}{|c|}{ Farmer Low } & 0 & 1 & 2 & 3 & 4 & 5 \\
\hline \multirow{6}{*}{ High } & 0 & 0 & 187 & 354 & 471 & 560 & 631 \\
\hline & 1 & 274 & 391 & 491 & 572 & 639 & 696 \\
\hline & 2 & 422 & 509 & 584 & 647 & 702 & 749 \\
\hline & 3 & 525 & 594 & 655 & 707 & 753 & 794 \\
\hline & 4 & 604 & 662 & 712 & 757 & 798 & 834 \\
\hline & 5 & 668 & 717 & 761 & 801 & 836 & 869 \\
\hline
\end{tabular}

Utility levels assigned to households and Famers for the five first units of the two water qualities 


\section{INSTRUCTIONS $^{7}$}

\section{Treatments PD and CD}

The aim of this experiment is to study how people make their decisions in certain contexts. Your decisions in the scenario explained below in detail, will be directly related to a monetary reward you will receive in cash at the end of the experiment. Any doubt you may have will be clarified personally to you by one of the organizers after you raise your hand. Beyond these questions, any other communication is strictly forbidden and is subject to immediate exclusion from the experiment.

You participate in a market consisting of the following features:

- There are two producers (1 and 2) and two commodities (product $H$ and product $L$ ). Specifically, product $H$ is water of High quality, while product $L$ is water of $L$ ow quality. Products $H$ and $L$ are substitutes, namely, consumers may, to a certain extent, substitute one type of water with the other.

- You are one of the two producers in this market. At the beginning of the session, the computer will indicate if you are producer 1 or 2 . Your competitor will be one (always the same) of the subjects in this room, randomly selected by the computer when the session starts [Treatment $C D$ : your competitor is the person who sits next to you]

- There are two types of consumers: households and farmers. Although they have different preferences with respect to the two types of water, they all prefer water of high quality (product $H$ ) to water of low quality (product $L$ ). That is, they are willing to pay more for $H$ than for $L$.

- The market will last for 50 rounds.

\section{Decision Making}

Your only decision as a producer is announcing the minimum price at which you are willing to sell each one from a maximum of 5 units you may sell of your product. Such announcements of minimum prices are called price bids. In order to make your decisions, you have to take into account that:

1. The extraction cost per additional unit extracted and by product is included in the "table of costs" bellow. Therefore, cost conditions for you and your competitor are identical, and they are expressed in ExCUs, a fictitious Experimental Currency Unit.

\footnotetext{
${ }^{7}$ The instructions to subjects were originally written in Spanish. Here we include a unified translated version for the two treatments, emphasizing the details that are specific to each one of them.
} 
2. Taking into account the cost structure in the table, you have to announce five minimum prices at which you are willing to sell each unit of the five units of your product. Therefore, your decision making consists of fixing 5 price bids for your product.

3. You should have in mind that, in order not to make any losses, price bids cannot be lower than the corresponding unit cost presented in the table.

4. Price bids cannot be decreasing. That is, your bid for the 1 st unit cannot be higher than your bid for the 2nd unit; the bid for the 2nd cannot be higher than the bid for the 3rd unit, and so on and so forth.

5. Observe in the table that the unit costs decrease with the stock size. At the beginning of the session, you have an initial stock size of 20 units. At the beginning of each round, you get three more units.

6. Your stock size can never exceed 20 units and, therefore, once 20 units are reached, any additional units you may receive are lost.

Table 3.

Unit extraction costs for the two water qualities

\begin{tabular}{|l|c|c|c|c|c|c|c|c|c|c|}
\hline Stock size & 20 & 19 & 18 & 17 & 16 & 15 & 14 & 13 & 12 & 11 \\
\hline Unit cost & 0 & 0 & 0 & 0 & 0 & 1 & 1 & 2 & 2 & 4 \\
\hline
\end{tabular}

\begin{tabular}{|l|c|c|c|c|c|c|c|c|c|c|}
\hline Stock size & $\mathbf{1 0}$ & $\mathbf{9}$ & $\mathbf{8}$ & $\mathbf{7}$ & $\mathbf{6}$ & $\mathbf{5}$ & $\mathbf{4}$ & $\mathbf{3}$ & $\mathbf{2}$ & $\mathbf{1}$ \\
\hline Unit cost & 7 & 11 & 18 & 30 & 50 & 82 & 135 & 223 & 368 & 607 \\
\hline
\end{tabular}

\section{Example}

Suppose that at the end of a round your stock size is 9 units. At the beginning of the new round, you get your additional 3 units (so that your stock now is 12 units). Observe in the table that, for a stock size of 12 units, the unit cost for the first five units extracted is the following:

- the cost of the 1st unit: 2 ExCUs

- the cost of the 2nd unit: 4 ExCUs

- the cost of the 3rd unit: 7 ExCUs

- the cost of the 4th unit: 11 ExCUs

- the cost of the 5th unit: 18 ExCUs 
In order not to make losses, each one of your bids should not be lower than the corresponding unit cost. Therefore, in this example, your bid for the 1 st unit should not be lower than 2 ExCUs (cost of the 1st unit); your bid for the 2nd unit should not be lower than neither 4 ExCUs (cost of this unit) nor your bid for the 1st unit; your bid for the 3rd unit should not be lower than neither 7 ExCUs nor your bid for the 2nd unit, and so on for the rest of the units.

In case you sell 5 units, the stock size at the beginning of next round would be 10 units (7 you kept plus 3 you get in the new round). If, given your bids for the five units, your sales are zero, your stock would be 15 units (12 you already had plus 3 you get at the beginning of the round).

\section{DeCISIONS}

You make decisions on the minimum price at which you are willing to sell each unit of your product. You will fill in all the boxes that appear at your computer screen with your price bids. In each box, you will also get information related to the corresponding unit cost. The bids you submit have to be integer numbers between zero and 2000 .

Although you may propose five different price bids, all units of the same type of water will be sold to consumers at a single price. This price will be your bid for the "last" unit sold of each product. The number of units sold each period is calculated by a program which simulates the optimal behaviour of consumers.

[Only Treatment CD] You have to make decisions for your product individually. However, since you share the same PC to submit your strategies, you may observe the decisions made by your competitor before pressing the "OK" button. Both you and your competitor have to agree on the moment in which you press the "OK" button, which means that you both have finished your own decision making process.

\section{Example}

In the example above, assume that your bids for your product are: 10 (for the 1st unit), 12 (for the 2nd), 14 (for the 3rd), 16 (for the 4th) and 20 (for the 5th). Given your bids, the program which simulates the optimal behaviour of consumers determines that 3 units of this product will be sold. The price at which you will sell the three units will be your bid for the 3rd unit, that is, 14 ExCUs.

\section{THE PROFITS}

Your net profit of selling each unit of a product will be the difference between the market price at which you sold all units (your unit income) and the corresponding unit extraction cost. Total profits will be the sum of the unit profits for all periods. 


\section{Example}

Taking again the previous example, if, at the beginning of a round, your stock size is 12 units, your total profits in that round will be 29 ExCUs, which are decomposed as follows:

i) 12 ExCUs for the 1st unit sold (14 ExCUs you receive for that unit minus 2 ExCUs it costs you extracting it).

ii) 10 ExCUs for the 2nd unit sold (14 ExCUs you receive for that unit minus 4 ExCUs it costs you extracting it).

iii) 7 ExCUs for the 3rd unit sold (14 ExCUs you receive for that unit minus 7 ExCUs it costs you extracting it).

\section{THE INFORMATION}

During decision making, the computer will provide you with a table simulating results conditional to your bid and cost for the corresponding unit in five possible scenarios: a) In case you only sell the 1st unit; b) If you just sell the first two units; ...e) In case you sell 5 units.

At the end of each round, the computer screen will show you the total profits obtained in that round, including information about unit cost, market price and number of units sold of each product, as well as your rival's price.

During the experiment, you will be provided with a screen containing the history of past rounds (market price for each product, number of units sold, total revenue and total profits.

\section{MonetARY REWARD}

Your monetary reward at the end of the session will be the sum of your profits accumulated in 15 rounds (randomly selected by the computer) of the total of 50 rounds, at an equivalence rate of 500 ExCUs=1 Euro. You will be paid in cash at the end of the session.

In order to make sure you understood correctly the market described above, we will proceed next to run a pilot session of 5 rounds. Please, feel free to make any questions you may have during this pilot session.

Thank you for your collaboration. Good luck!

\section{ON GAMES WITH CONFIRMED STRATEGIES}

Following Attanasi et al. (2011) we describe in this part of the appendix the prisoner's dilemma game with confirmed proposals. Consider the following payoff matrix corresponding to a static prisoners' dilemma with the well-known dominant strategy equilibrium ( $\mathrm{A}$, S) played by two players, 1 (rows) and 2(columns) in the following way: 


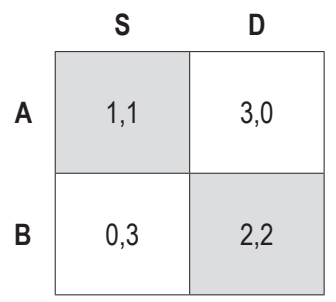

The dynamic game with confirmed proposals works as follows: Player 1 announces a strategy from the set $\{A, B\}$. Player 2 observes the announcement and chooses to announce a strategy from the set $\{S, D\}$ subject to 1 's confirmation of the announced strategy. If player 1 confirms the initial strategy, the bargaining process ends in a "confirmed agreement' and strategies are played as announced. Otherwise, player 1 may not confirm the strategy profile resulting from his initial announced strategy and 2's response to it. Then, a different strategy is announced in response to 2's previously announced strategy. If player 2 confirms the strategy profile, the game ends as explained before, otherwise 2 may not confirm the resulting strategy profile and make a new proposal. This procedure continues until an agreement is reached by a player's confirmation of his announced strategy and his rival's response to it. This is a dynamic game with complete and perfect information that can be represented in the following way:

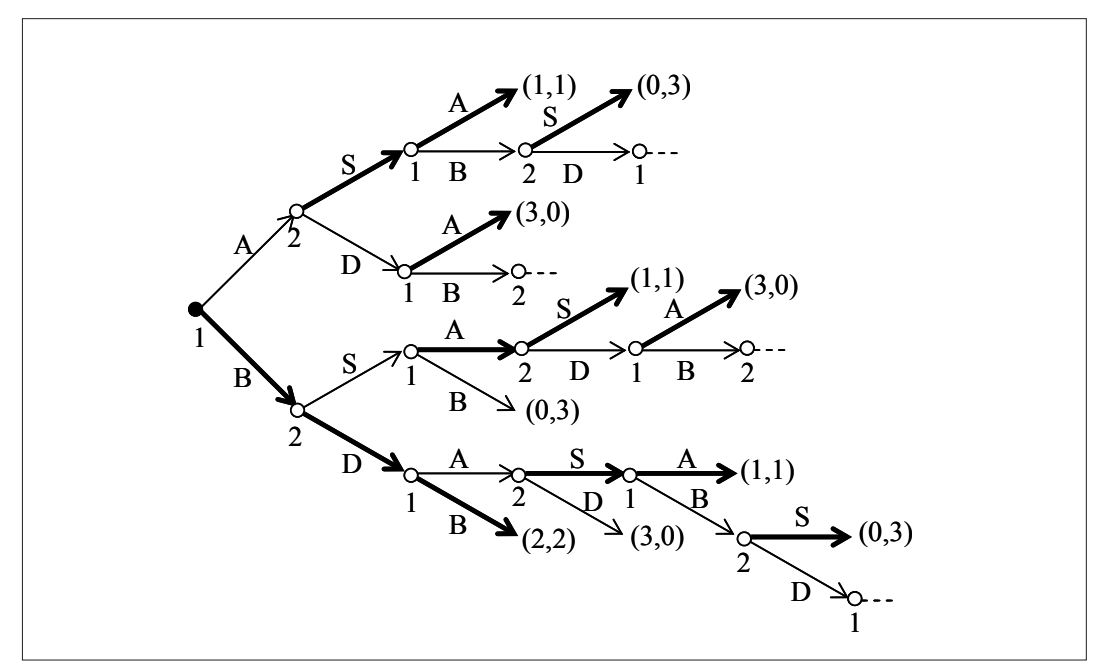

The arrows drawn in thin (light) lines correspond to actions which are not going to be chosen by the corresponding player. Thus, the subgame perfect Nash equilibrium (SPNE) of the game is the cooperative (Pareto optimal) strategy profile (B, D). Therefore, the SPNE of the "confirmed strategies" version of a prisoners' dilemma is the cooperative (Pareto optimal) outcome. 